\author{
ISSN: 2757-6485
}

$2021 \& 2$ (2)

\title{
Taekwondo'nun Olimpik Branşı Olan Gyorugi Dalının Özellikleri ve Yenilikleri Üzerine Bir İnceleme
}

\author{
"A Study on the Characteristics of Kyorugi that is the Olympic Branch of \\ Taekwondo and Innovations in It"
}

\author{
Duygu SEVINÇ YILMAZ1
}

\section{DERLEME}

\section{Tarihce}

Yayın Geliş Tarihi: 7 Haziran 2021

Kabul Tarihi: 13 Temmuz 2021

Online Yayın Tarihi: 31 Ağustos 2021

DOİ: http://dx.doi.org/10.29228/anatoliasr.11

\section{Yazarlarla İletişim}

1- (Sorumlu Yazar) Erzincan Binali Yıldırım Üniversitesi, Spor Bilimleri Fakültesi,

Erzincan, Türkiye

24duygusevinc24@gmail.com

https://orcid.org/0000-0002-7737-564X

\section{Yazar Katkıları \\ Tüm yazarlar çalışmanın konseptine ve tasarımına katkıda bulundu.}

\section{Finansman}

$\mathrm{Bu}$ çalışma herhangi bir kurum/kuruluştan maddi destek almadı.

\section{Çıkar Çatışması}

Yazarlar çıkar çatışması olmadığını beyan ediyorlar.

\section{Şeffaflık}

Yazarlar, çalışmada hiçbir hayati özelliğin ihmal edilmediğini, dürüst, doğru ve şeffaf bir anlatım ile raporlaştırıldığını ve herhangi bir tutarsızlık olmadığını beyan etmişlerdir.

\section{Etik}

$\mathrm{Bu}$ çalışmada bilimsel etik kriterlerine uyulmuştur.

\section{Referans Gösterimi}

Sevinç Yılmaz, D. (2021). Taekwondo'nun Olimpik Branşı Olan Gyorugi Dalının Özellikleri ve Yenilikleri Üzerine Bir İnceleme / A Study on the Characteristics of Kyorugi that is the Olympic Branch of Taekwondo and Innovations in It, Anatolia Sport Research, 2(2): $1-10$.

Copyright (C) 2021 by Anatolia Sport Research

\section{ÖZET}

Amaç: Bu araştırmanın amacı, Taekwondo branşının tarihçesini, kurallarını, ekipmanlarını ele alırken, bu branşın olimpik dalı olan kyorugi (müsabaka)'nin özelliklerini ve bu dalda yapılan yenilikleri, sporcuya olan katkılarını incelemektir.

Materyal ve Metod: Çalışmanın yönteminde literatür araştırmalarının incelemesi yapılarak sonuçların karşılaştırıldığı mikro analiz yöntemi kullanılmıştır. Literatür taramasında PubMed, Google Scholar ve Research Gate veri tabanlarından faydalanılmıştır.

Bulgular: Taekwondo branşının olimpik bir spor olması ve devamında ekipmanlarda ve kurallarda yenilikler yapmaya devam etmesi popüler bir branş olarak spor dünyasında yerini korumasına yardımcı olmaktadır.

Sonuç: Branşta yapılan kural ve puanlama siteminde ki değişiklikler sporcuların daha aktif olmasına, müsabakaların daha kaliteli geçmesine, teknik kapasitenin artmasına ve puanlama üzerindeki şaibelerin kalkmasına yardımcı olmaktadır. Aynı zamanda ekipmanlarda yapılan değişiklikler sporcuların yaralanma indeksinde düşüşlere neden olmaktadır.

Anahtar Kelimeler: Gyorugi, Taekwondo, Taekwondo Kuralları

\section{ABSTRACT}

Aim: The purpose of this research is to examine characteristics of kyorugi (race) that is the Olympic branch of Taekwondo, innovations made in this branch and its contributions to the athlete while examining the history, rules and equipment of the branch Taekwondo.

Material and Method: The method of the study is micro-analysis method with which the results were compared by examining the literature researches. PubMed, Google Scholar and Research Gate databases were used in the literature review.

Results: Taekwondo is an Olympic sport and continues to make innovations in the equipment and rules, which helps it maintain its place in the world of sports as a popular branch.

Conclussions: The changes in the rules and scoring system of the branch help the athletes to be more active, the competitions to be more quality, the technical capacity increase and the questionable scoring eliminate. Also the changes made in the equipment decrease injury index of the athletes.

Keywords: Kyorugi, Rules of Taekwondo, Taekwondo 


\section{GíRiş}

Taekwondo (TKD), bir felsefe çerçevesinde el ve ayak teknikleri kullanarak yapılan savunma sanatıdır (Kazemi Perri, Soave, 2010). Taekwondo, hızlı vuruşları ve dinamik ayak hareketleri ile ünlüdür. Kore' de binlerce yıl önce ortaya çıkan ve dünya çapında 120 milyondan fazla kişinin aktif olarak katılım gösterdiği bir savunma sporudur (Birrer,1996).

TKD branşı birçok kompleks özelliği bünyesinde bulunduran bir branştır. Bu kompleks yapıyla birlikte branşa özgü teknikleri uygulamak ciddi bir antrenman yükü oluşturmaktadır. Antrenman programlamasında tekniklerin koordineli bir şekilde uygulanabilmesi için iyi bir esneklik, hız, denge, koordinasyon vb. özellikler gerekmektedir (Lystad, Pollard, Graham 2009). Güder (2015)'e göre taekwondoda müsabakalarında birebir temasta bulunulduğundan dolayı iyi bir kuvvete, anaerobik güçe ihtiyaç duyulmaktadır. TKD branşında ayak (tekme) vuruşlarının önemi büyüktür. Müsabakaların teknik analizlerinin yapıldığı çalışmalara dayanarak \%80 gibi büyük bir oranını ayak tekniklerinin oluşturduğu bilinmektedir (Shirley,1992; Mavi,2018). Müsabaka içerisinde teknikleri uygulamak için yüksek düzeyde patlayıcı bacak gücüne, aerobik-anaerobik dayanıklılığa ihtiyaç duyulmaktadır (Markovic, Misigoj-Durakovic, Trninic 2005; Heller, Peric, Dlouha, Kohlikova, Melichna, Novakova 1998).

TKD sıklet sporu olduğundan dolayı performans belirleyiciler arasında boy uzunluğu, vücut ağırlığı, yaş, sporcu yaşı gibi faktörler önem arz etmektedir. Sporcunun müsabaka performansı aynı zamanda rakibin taktik, teknik, psikolojik durumlarına da bağlıdır (Pieter ve Heijmans, 2003). Bu yüzden de TKD eğitimleri küçük yaşlardan itibaren başlamaktadır. Fiziksel eğitimlerin başlıca amaçları arasında sporcuların hem sağlıklı bir gelişim (fiziksel, psikolojik) seyretmeleri hem de müsabaka koşullarını yerine getirebilmeleri için fizyolojik hazırlıkları yapabilmeleri sayılabilmektedir (Markovic, Misigoj-Durakovic, Trninic 2005).

\section{Taekwondo’ nun Tarihçesi ve Türkiye’ de Gelişimi}

1971 yılında TKD ulusal askeri sanat olarak aday gösterilmiştir. Bu olaydan sonra Güney Kore'nin Kukkiwon kentinde çeşitli Taekwondo müsabakaları düzenlenmeye başlamış ve 1972' de merkezi spor salonu kurulmuştur. 1973' te 166 ülkenin üye olduğu Dünya Taekwondo Federasyonu ortaya çıkmıştır. 1973' te ilk Dünya Taekwondo Şampiyonası düzenlenmiştir. 1974' te resmi olarak Asya Oyunlarına kabul edilmiştir. 1975' te Amerika Birleşik Devletleri Amatör Atletler Birliği tarafından resmi spor branşı kabul edilmiştir (Un-young,2002). IOC tarafından 1980 yılında olimpik bir spor olmuştur. 1998 Seul ve 1992 Barselona Olimpiyatlarında gösteri sporu olarak yer almıştır. 2000 Sidney Olimpiyatlarında ise resmen oyunlara dahil edilmiştir (Moenig ve Kim, 2016).

Bu sporun ülkemize geliş tarihi ise 1960' lı y1llara rastlamaktadır. 1968 yılında Judo Federasyonuna bağlı olarak faaliyetlerini sürdürmüş ve ülkemiz ilk defa 1976 yllında düzenlenen Avrupa Şampiyonasına katılarak takım halinde Avrupa 2.si olmuştur. 1981 yılında Judo Federasyonundan ayrılıp, Mithat Kor başkanlığında Taekwondo Federasyonu kurulmuştur. 1982 yılında Prof. Dr. Esen BEDER başkanlık, İsmet IRAZ ise teknik direktörlük görevini üstlenmesi ile birçok başarıya imza atılmıştır (Canbaz, 2014). Ülkemizde bu branşın yayılması ve başarı grafiğinin sürekli olarak artması devam etmektedir.

TKD branşı 3 bölümden oluşmaktadır (Canbaz, 2014):

\section{- Poomse (Self Defans)}


- Kırışlar (Kyokpa)

- Müsabaka (Kyorugi)

Poomse, daha önceden belirlenmiş hareket dizilerini belirli kurallar ve puanlama içerisinde (nefes, denge, teknik doğruluğu vb.) uygulamaktır. Kırışlar çeşitli malzemeleri (beton, tahta, buz, mermer vb.) el ayak teknikleri kullanarak kırmaktır. Yarışma niteliğinden daha çok gösteri niteliği taşımaktadır. Müsabakalar ise, rakiple karşılıklı bir şekilde, belirli kurallar çerçevesinde TKD' ye özgü teknikleri kullanarak sporcuların yarışmasıdır.

\section{Müsabaka (Kyorugi) Kuralları}

Bu branşta her 4 ayda bir kuşak değiştirme sınavı yapılmaktadır. Kuşak renkleri beyaz, beyaz-sarı, sarı, sarı-yeşil, yeşil, yeşil-mavi, mavi, mavi-kırmızı, kırmızı, kırmızı-siyah, siyah şeklindedir. Müsabakalara katılmak için her kategoride minimum sağlanması gereken kuşak rengi şartı bulunmaktadır. Minikler kategorisinde mavi-kırmızı kuşak ve üzeri, yıldızlar, gençler, ümitler ve büyükler kategorisinde ise kırmızı-siyah ve üzeri kuşak derecesine sahip sporcular yarışmalara katılabilmektedir (TTF, 2021). Müsabakalara katılım için sadece kuşak derecesi yeterli olmamaktadır. Yarışmaya katılabilmek için söz konusu kategorinin yaş ve sıklet şartını da yerine getirmek gerekmektedir (WTF, 2019). Müsabakalara ayrı cinsiyetlerde (kadın-erkek) katılım sağlanmaktadır. Müsabakadan 1 gün önce sporcuların tartısı yapılmaktadır. Sporcular daha önce belirttikleri sıkletten farklı sıklette yarışamazlar. Sporcuların 2 tartı hakkı bulunmaktadır. Belirttiği sıklette tartılırken +100 gr. toleransı bulunmaktadır. 2 tartı hakkı sonucunda belirttiği kilograma ulaşamazsa sporcu elenmektedir.

Müsabakalar $8 * 8$ metrelik petek şekilde dizilmiş tatemi ile kaplı bir kortta yapılmaktadır. Sporcular belirtilen alanın dışına çıktıklarında uyarı cezası almaktadırlar. Alanın dış kısmında 3 hakem, orta kısımda bir hakem görev almaktadır.

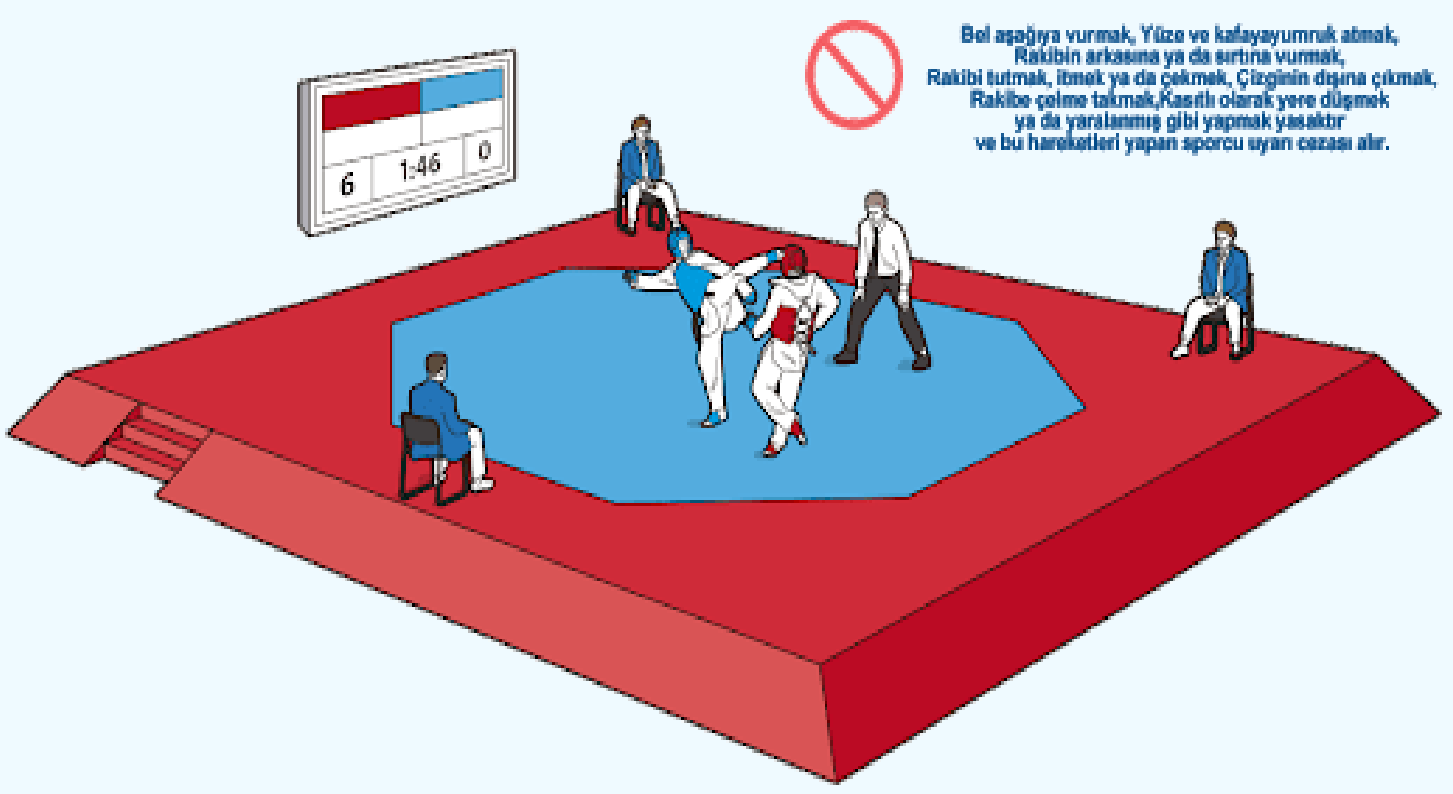

Resim 1: Taekwondo müsabaka alanı ve hakemlerin konumları 
Müsabakalar minik-yıldız kategorilerinde 1,5 dakikadan, diğer kategorilerde ise 2'şer dakikadan 3 raunt ve raunt aralarında 1 dakikalık dinlenme molası verilerek uygulanmaktadır (Birrer, 1996; Toskovic, Blessing, Williford, 2004). 3. Raunttun sonunda puanı yüksek olan kişi müsabakayı kazanmaktadır. 3 raunttun sonunda beraberlik olması durumunda 4. raunt yapılmaktadır. Altın vuruş olarak tabir edilen rauntta ilk puanı alan kişi galip sayılmakta ve bir üst tura çıkmaya hak kazanmaktadır. Müsabakalar eleme sistemiyle yapılmaktadır. Bir sporcu final müsabakasına kadar sıkletindeki sporcu sayısına göre ortalama olarak 7-8 maç yapmaktadır. O gün içerisinde müsabakası olan sıkletin yarışması tamamlanmaktadır.

Son yıllarda, Dünya Taekwondo Federasyonu tarafından önemli kural değişiklikleri yapılmıştır (Moenig, 2015, 2017). Müsabaka kuralları çerçevesinde yere düşmek, surata yumruk atmak, belden aşağı vuruş yapmak, tutmak ve müsabaka alanı dışına çıkmak yasaktır. Bu ve buna benzer tutumları sergileyen sporcuya 1 ceza puanı verilmektedir. Toplamda 10 ceza puanı alan sporcu puan üstünlüğü olsa bile diskalifiye edilmektedir (WTF, 2017). Puanlamalar gövde ve kafaya uygulanan çeşitli teknikler ve zorluk derecelerine göre yapılmaktadır.

Müsabakalar 3 kamera ile kayıt altına alınmaktadır. Antrenörlerin video replay uygulaması denilen bir sistem aracılığıyla itirazları olması durumunda kamera kayıtları izlenmekte ve itiraz olunan pozisyon değerlendirilmektedir (WTF, 2017). Masa başı hakemi durumu değerlendirip kararı anında ilan etmektedir.

\section{Müsabakalarda (Kyorugi) Kullanılan Ekipmanlar}

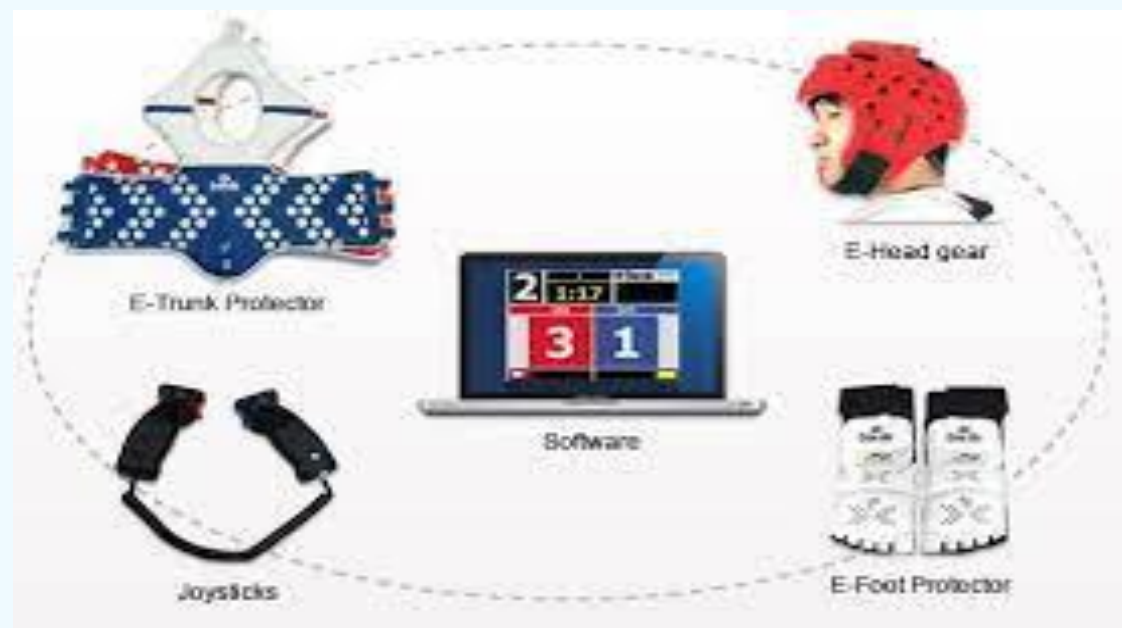

Resim 2: Taekwondo müsabakalarında kullanılan elektronik ekipmanlar

\section{1- Elektronik Safeguard (Gövde koruyucusu)}

$\mathrm{Bu}$ ekipmanı sporcular gövdelerine giyinmektedirler. Tamamen elektronik olan bu koruyucu sayesinde puanlamalar otomatik olarak yapılmaktadır. Sporcunun yaşına ve kategorisine göre Dünya Taekwondo Federasyonu tarafından vuruş şiddeti (basınç-bar) ayarlanmaktadır. Yeterli basınç şiddeti ile doğru teknik vuruşu gerçekleştiğinde skorborda puan yansımaktadır. Örneğin palding-chagi tekniği, sporcunun ayaküzeri ile yapması gereken bir teknik çeşididir. Sporcu bu tekniği yeterli basınç şiddetiyle ve ayağının üzeri ile uyguladığında puan alabilmektedir. Sporcular bu bölgeye ayaklarının altı veya 
üzeri ile vuruş yapabilmektedirler. Bu koruyucu sayesinde sporcular darbeleri daha az şiddette hissetmektedirler.

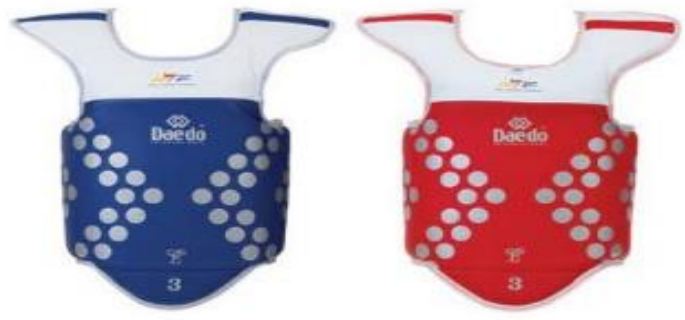

Resim 3: Elektronik gövde koruyucusu

\section{2- Elektronik Kask (Kafa koruyucusu)}

Sporcular kafalarına taktıkları bu koruyucu sayesinde puanlamalar otomatik skorborda yansımaktadır. Ayağının üzeri ve altı ile bu bölgeye vuruş yapabilmektedirler. Kafa bölgesine yapılan vuruşların puan değeri yüksek olmasına rağmen, bu bölgeye vuruşlar zor olabilmektedir. Bu koyucunun diğer bir faydası ise sporcuların kafa bölgesine aldıkları darbeleri minimuma indirmesidir.

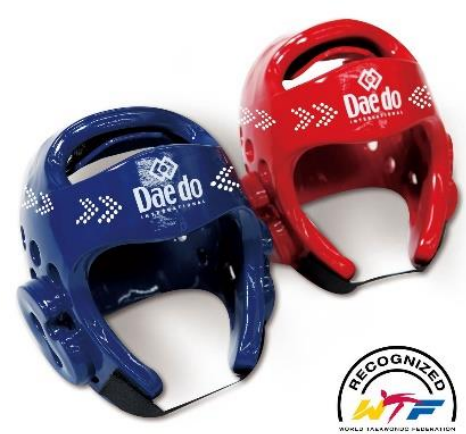

Resim 4: Elektronik kafa koruyucusu

\section{3- Elektronik Ayaküstü Koruyucusu}

Sporcuların ayak üzerine taktıkları bir koruyucu çeşididir. Vuruş esnasında sporcuların sakatlıklarını en aza indirgemeye yardımcı olmaktadır. Aynı zamanda ayaküstü koruyucusunun üzerinde bulunan sensörler ile gövde koruyucusunda ve kaskta bulunan sensörler doğru teknik ve yeterli basınç ile buluştuğunda puan alınılabilmektedir. 


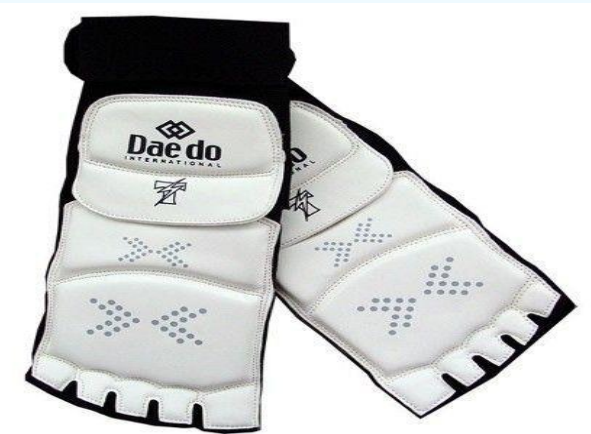

Resim 5: Elektronik ayaküstü koruyucusu

\section{4- Eldiven}

Sporcuların ellerine giydikleri bir koruyucu türüdür. Sporcuların darbelere karşı parmaklarını korumak amacıyla kullanılmaktadır. Bu koruyucu ile sadece gövdeye yumruk atarak puan alınmaktadır. Puanlama ise hakem kanaati ile manuel olarak yapılmaktadır.

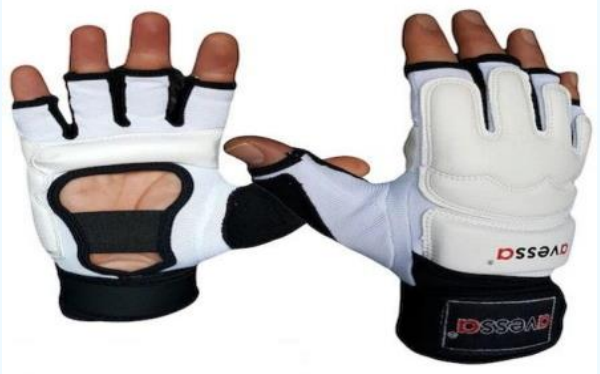

Resim 6: Eldiven

\section{5- Kol- Kaval Koruyucusu}

Sporcuların Taekwondo elbisesinin içerisine taktıkları bir koruyucu türüdür. Sporcunun her iki kola ve her iki kaval kemiklerine taktıkları bu koruyucu türü sayesinde sakatlıklar minimuma inmektedir. Kola takılan koruyucu sayesinde sporcular rahatlıkla blok yapabilmekte, aynı zamanda rakibin puan alımını engelleyebilmektedirler. Kaval kemiklerine takılan koruyucu sayesinde sporcuların teknik atarken bloğa rağmen çekinmeden teknik atmasına imkan vermektedir.

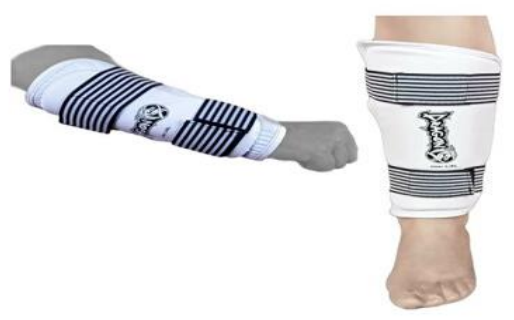

Resim 7: Kol- Kaval koruyucusu 


\section{6- Kasık (Kogi) Koruyucusu}

Kadın ve erkeklerin kasıklarını koruyabilmeleri amacıyla elbise içerisine giydikleri bir koruyucu türüdür.
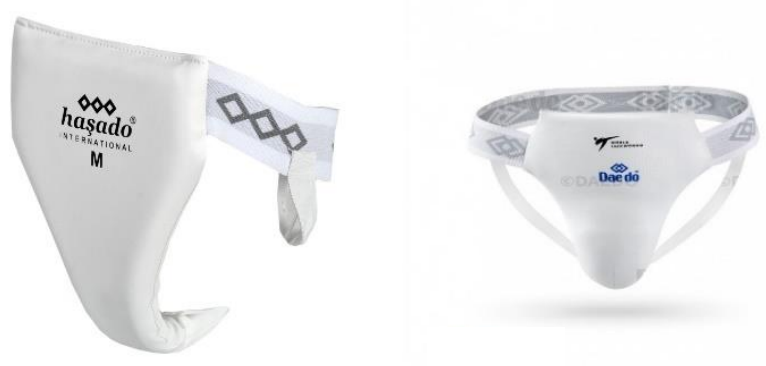

Resim 8: Kadın- Erkek Kasık Koruyucusu

\section{7- Dişlik}

Sporcular bu ekipmanı müsabaka içerisinde üst dişlerine takmaktadırlar. Hazır olarak bulunacağı gibi diş hekimlerinden kendi dişlerine özel de yaptırabilmektedirler. Her raunda çıkarken orta hakem iki sporcunun da dişliğini kontrol etmektedir. Dişliğin olmaması ya da standart dışı olması durumunda müsabakayı başlatmamaktadır.

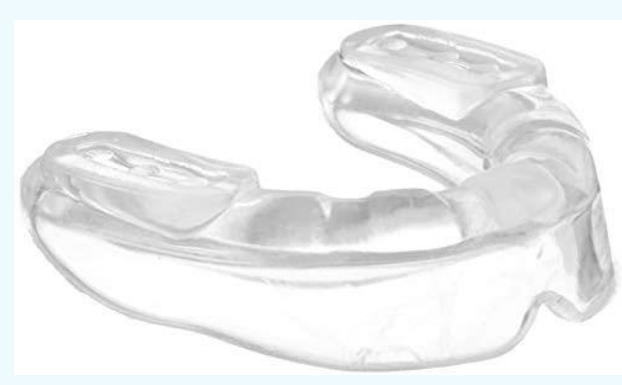

Resim 9: Dişlik

Yukarıda sporcuların her müsabakaya çıkarken takmak zorunda oldukları ekipmanlardan bahsedilmiştir. Müsabakaya çıkarken elektronik gövde koruyucusu ve elektronik kask müsabaka anında federasyon tarafından verilmektedir. Diğer koruyucular ise sporcuların şahsi malzemeleridir. Müsabaka alanına gelmeden önce kontrol hakeminden geçerek ekipmanların tam olup olmadığı ve müsabakaya uygun olup olmadığı kontrol edilmektedir. Kontrol hakemi aynı zamanda sporcuların el-ayak tırnaklarını da kontrol etmektedir. Tırnakların uzun olması durumunda sporcu müsabakaya çıkarılmamaktadır. Bunun yanı sıra sporcuların saçlarında (özellikle kadın sporcularda) tel toka veya sert bir cisim olup olmadığı kontrol edilmektedir.

\section{Müsabakalarda (Kyorugi) Puanlama}

Gövdeye yumruk ile vuruşlar 1 puandır. Ayak teknikleri ile vuruşlar 2 puan, dönerli vuruşlar ise 4 puandır. Kafa hizasına sadece ayak ile vuruş yapılmaktadır. Yapılan vuruşlarda ise, puanlamalar 3 puan, dönerli tekniklerin puanlaması ise 5 puan olarak değerlendirilmektedir. Sporculara kural ihlallerinde 
verilen uyarı cezası ise 1 puan olarak rakibin hanesine yansımaktadır. Sporcuyu sakatlamak veya müsabakaya devam ettirmemek için yapılan illegal hareketler diskalifiye ile sonuçlanabilmektedir.

\section{MATERYAL VE METOD}

Çalışmanın yönteminde literatür araştırmalarının incelemesi yapılarak sonuçların karşılaştırıldığı mikro analiz yöntemi kullanılmıştır. Literatür taramasında PubMed, Google Scholar ve Research Gate veri tabanlarından faydalanılmıştır.

\section{TARTIŞMA VE SONUÇ}

Janowski, Zieliński, Kusy, 2019 yılında yaptıkları çalışmada Taekwondo müsabaka kurallarında yapılan değişikliklerin sporcuların fizyolojik ve kinematik profilini ne ölçüde etkilediğini tespit etmeye çalışmışlardır. 2 yıl boyunca 22 (kadın-erkek) sporcuyu takip etmişlerdir. Toplamda eski kurallarla yarışan 133, yeni kurallarla yarışan 125 müsabakayı analiz etmiş̧lerdir. Sonuç olarak kurallar değiştikten sonra sporcuların daha dinamik vücut hareketlerine, yüksek yoğunlukta yarışmaya, müsabaka sonrası daha fazla yorgunluğa eğimli olduklarını tespit etmişlerdir.

Janowski, Zieliński, Ciekot-Sołtysiak, Schneider, Kusy (2020) yaptıkları başka bir çalışmada müsabaka kuralı değişikliğinden önce ve sonra branşa özgü yapılan antrenmanları karşılaştırmışlardır. 15 elit sporcuya iki yıl boyunca 240 antrenman yaptırarak çalışmalarını analiz etmişlerdir. Yapılan kural değişiklikleri pik solunum hızında, enerji harcamasında, egzersiz sonrası kan laktat düzeyinde artışlara neden olmuştur. Eski kurallardan yeni kurallara geçişte fizyolojik değişkenlikler \%2,4-38,5, kinematik değişkenlikler ise \%2,9-15,5 arasında değişkenlik göstermiştir.

Pekin Olimpiyatları ile 11. Kickboks oyunlarının karşılaştırıldığı çalışmada, TKD branşına özgü yeni kurallar ve yeni elektronik puanlama sistemi değerlendirilmiştir. Çalışma yöntemi olarak video analiz yöntemi kullanılmıştır. Çalışma sonucunda TKD sporcularının kişisel puanlarının, elektronik kask sayesinde kafaya vuruşlarının arttığını ve dönerli tekniklerin müsabakalarda önem kazandığını bulgulamıştır (Xiangjun, 2012).

Viscogliosi, (2013) yılında yaptığı araştırmada, 2008 Olimpiyat Oyunları ile Olimpiyat Oyunları için yapılan eleme müsabakalarından (2011-2012 yılları) 3 tanesinin incelemesini yaparak eski -yeni kural sistemini ve puanlama sistemini karşılaştırmıştır. 2008 yılında eski sistemde yapılan 380 müsabakanın incelemesini yapmış ve 55 yaralanma $(\% 14,5), 3$ nakavt $(\% 0,8)$ tespit etmiştir. Yeni sistemde yapılan 1180 müsabakayı incelemiş ve 15 yaralanma $(1,3), 2$ nakavt $(\% 0,17)$ olduğunu bildirmiştir. Sonuç olarak yeni puanlama sisteminde (elektronik puanlama sistemi) yeni kurallarla yarışmak yaralanma oranını 11, nakavt olma oranını ise 5 kat azaltmaktadır.

Sevinç (2016) büyükler kategorisinde aktif olarak yarışan 14 lisanslı sporcu üzerinde elektronik puanlama sistemiyle yapılan antrenmanların performansa katkısının olup olmadığını incelemiştir. Sporcuların teknik becerilerinin geliştirilmesi ve mevcut durumlarının tespit edilmesi amacıyla, ikili teknik kombinasyonlardan üç atak, üç kontra atak olmak üzere toplam altı teknik belirlenmiştir. Sporcular 5 hafta boyunca 2'şer saat olmak üzere haftada 3 gün antrenman yapmışlardır. Çalışmanın başlangıcında sporcuların, ikili kombine tekniklerden sadece bir vuruştan puan aldıkları, hatalı teknik vuruşlardan kaynaklı puan alamadıkları ve teknikleri uygularken daha uzun süre kullandıkları tespit edilmiştir. 5 haftalık elektronik yelekle çalışma sonucunda ise, daha kısa sürede vuruşları 
tamamladıkları, teknik kapasitenin artmasına paralel olarak aldıkları puanlarda artış olduğu sonucuna ulaşı1mıştır.

Başka bir çalışmada dövüş sporları için kablosuz sensörlü puanlama sistemi ve bu sistemin antrenman tekniklerini geliştirdiği bildirilmiştir (Partridge, Hayes, James, Hill, Gin, Hahn, 2005). Elektronik sistemle antrenman yapmanın branşa özgü tekniklerin kullanımını ve ayak hâkimiyetini geliştirdiği ifade edilmektedir (Sevinç,2017). Song, Jeon, Park, An, Hwang, Lee, Lee (2010) elektronik sistemle çalışmanın etkilerini araştırdığı çalışmada 10 kişiye memnuniyet anketi uygulamış ve kullanıcıların genel olarak sistemden memnun olduklarını bildirmiştir.

Sonuç olarak, teknolojinin gelişimine paralel olarak müsabakalarda kullanılan elektronik sistem daha objektif bir değerlendirme sağlamanın yanı sıra adil bir sonucunda ortaya çıkmasına yardımcı olmaktadır (Tasika, 2013; Song, Jeon, Park, An, Hwang, Lee, Lee 2010; Song, Woo, Min, Lee, 2010). Sporcuların performanslarını, teknik kapasitelerini anında değerlendirmeye yardımcı bu sistem sayesinde sporcular, antrenörler başarı grafiklerini büyük ölçüde artırmaktadır (Leveaux, 2010).

Ülkemizde sporcu sayısının futboldan sonra en fazla olduğu bu branşta rekabet günden güne artmaktadır. Müsabaka kurallarının değişmesine paralel olarak antrenörler ve sporcular ilgili ekipmanlarla antrenmanlarını sürdürmenin yanı sıra, oyun kurallarına uygun teknik- taktik antrenmanları yaparak daha etkili sonuçlar alacaklardır. Sporcunun ekipmanlara ve kurallara adaptasyonu antrenman programlarında bu değişikliklere yer verilmesiyle gerçekleşebilmektedir. Elektronik sistem aracılığıyla yapılacak antrenmanlar sporcuların eksik yönlerini daha net görmelerine imkan tanıyacaktır.

\section{KAYNAKLAR}

Birrer R. B. (1996). Trauma epidemiology in the martial arts: the results of an eighteen-year international survey. The American Journal of Sports Medicine. 24(6_suppl):S72-9. PMID: 8947435

Canbaz, M. (2014). Taekwondo da antrenör. Atlas Akademi.

Güder, F. (2015). Elit taekwondocu kadınlarda Poomseci ve gyorugicilerin fiziksel ve fizyolojik özelliklerinin karşılaştırılması. (Master's thesis, Niğde Üniversitesi/Sosyal Bilimler Enstitüsü).

Heller, J., Peric, T., Dlouha, R., Kohlikova, E., Melichna, J., \& Novakova, H. (1998). Physiological profiles of male and female Taekwondo (ITF) black belts. J Sport Sci 16: 243-249.

Janowski, M., Zieliński, J., \& Kusy, K. (2019). Exercise response to real combat in elite taekwondo athletes before and after competition rule changes. Journal of strength and conditioning research.

Janowski, M., Zieliński, J., Ciekot-Sołtysiak, M., Schneider, A., \& Kusy, K. (2020). The effect of sports rules amendments on exercise intensity during taekwondo-specific workouts. International Journal of Environmental Research and Public Health, 17(18), 6779.

Kazemi, M., Perri, G., \& Soave, D. (2010). A profile of 2008 Olympic Taekwondo competitors. The Journal of The Canadian Chiropractic Association. 54(4):243. PMID: 21120015

Leveaux, R. R. (2010). Technology driving changes in competitor decision making and match management. 14th International Business Information Management Association Conference, İstanbul, Turkey, June 23 - 24.

Lystad, R. P., Pollard, H., \& Graham, P. L. (2009). Epidemiology of injuries in competition taekwondo: A metaanalysis of observational studies. Journal of Science and Medicine in Sport, 12(6), 614-621.

Markovic, G., Misigoj-Durakovic, M., \& Trninic, S. (2005). Fitness profile of elite Croatian female taekwondo athletes. Coll Antropol 29: 93-99.

Moenig, U.(2015). Rule and equipment modification issues in World Taekwondo Federation (WTF) competition. Ido Mov Cult J Martial Arts Anthrop 15: 3-12, 37.

Moenig, U., \& Kim, M. (2016). The invention of Taekwondo tradition, 1945-1972: When mythology becomes 'history.'. Acta Koreana, 19(2), 131-164.

Moenig, U. (2017). Dominant features and negative trends in the current World Taekwondo Federation (WTF) competition system. Ido Mov Cult J Martial Arts Anthrop 7: 56-67. 
Partridge, K., Hayes, J. P., James, D. A., Hill, C., Gin, G., \& Hahn, A. (2005). A wirelesssensor scoring and training system for combative sports. Proc. SPIE 5649, Smart Structures, Devices, and Systems II, 5649, 402-408.

Pieter, W., \& Heijmans, J. (2003). Training and competition in taekwondo. Journal of Asian Martial Arts, 12(1), 9-23.

Sevde, M. (2018). Technical analysis of 2007 and 2017 World Taekwondo Women and Men championship finals. Türk Spor ve Egzersiz Dergisi, 20(3), 256-262.

Sevinç, D. (2016). Electronic body protector for the development of taekwondo athletes' technical skills: reflections on performance/ Taekwondocuların teknik becerilerinin geliştirilmesinde elektronik yelek: Performansa yansımaları. $\dot{G} \ddot{U}$ Spor Bilimleri Dergisi, 1303(1414), 1-10.

Sevinç, D. (2017). Comparıson of the effects of high level technıcal strıkes of taekwondo athletes on the electronıc head gear before and after trainıng. The Online Journal of Recreation and Sports, 6(4), 13-27.

Shirley, M. (1992).Sports performance series: The taekwondo side kick: A kinesiological analysis with strength and conditioning principles. Strength Cond J, 14: 7-8.

Song, Y., Jeon, Y., Park, G., An, H., Hwang, T., Lee, H., \& Lee, S. (2010). Development of taekwondo trainer system for training on electronic protector with hitting target indicator. International Journal of Computer Science and Network Security, 10(6), 51-56.

Song, Y. R., Woo, Y. S., Min, H. K., \& Lee, S. M. (2010). Development of digital taekwondo trainer system based on electronic protector for analysis hitting pattern. RESKO Technical Conference, 11, 77-80.

Tasika, N. (2013). Reliability \& linearity of an electronic body protector employed in taekwondo games: a preliminary study. Performance Analysis Workshop, Alicante, Spain 2 - 5 April.

Toskovic, N. N., Blessing, D., \& Williford, H. N. (2004). Physiologic profile of recreational male and female novice and experienced Tae Kwon Do practitioners. Journal of Sports Medicine and Physical Fitness, 44(2), 164.

TTF, (2021).https://www.turkiyetaekwondofed.gov.tr/default.asp?SayfaID=4. ErişimTarihi: 01.07.2021

Un-yong, K. (2002) Taekwondo Textbook, Çeviri: Bayram Tıraş, Damla Yayıncılık: Ankara, syf: 9-10.

Viscogliosi, P. (2013). How the new taekwondo rules have decreased the injuries and concussions since 2008. British journal of sports medicine, 47(5), e1-e1.

Xiangjun, L. I. (2012). Score Skills of the 16th Asian Games of Taekwondo Competition in New Rules [J]. Journal of Shenyang Sport University, 2.

World Taekwondo Federation, (2017). Competition Rules \& Interpretation. Seoul, Korea:, Available at: http://www.worldtaekwondo.org. Erişim tarihi: 30.06.2021.

WTF(2019).http://www.worldtaekwondo.org/wp-content/uploads/2019/08/WT-Ranking-BylawMay-152019.pdf. Erişim adresi: 30.06.2021. 